\title{
Click

\section{BMPix and PEAK tools: New methods for automated laminae recognition and counting-Application to glacial varves from Antarctic marine sediment}

\section{E. Weber}

Institute of Geology and Mineralogy, University of Cologne, Zuelpicher Strasse 49a, D-50935 Cologne, Germany (michael.weber@uni-koeln.de)

\section{Reichelt}

Institute of Geology and Mineralogy, University of Cologne, Zuelpicher Strasse 49a, D-50935 Cologne, Germany

Now at Department of Geosciences, Marine Geophysics, University of Bremen, Klagenfurter Strasse, D-28359 Bremen, Germany

\section{G. Kuhn}

Alfred-Wegener-Institute for Polar and Marine Research, Am Alten Hafen 26, D-27568 Bremerhaven, Germany

\section{Pfeiffer}

Institute of Geology and Mineralogy, University of Cologne, Zuelpicher Strasse 49a, D-50935 Cologne, Germany

\section{B. Korff}

Helmboltz-Institut fuer Strablen- und Kernphysik, University of Bonn, Nußallee 14-16, D-53115 Bonn, Germany

\section{J. Thurow}

Department of Earth Sciences, University College London, Gower Street, London WC1E 6BT, UK

\section{W. Ricken}

Institute of Geology and Mineralogy, University of Cologne, Zuelpicher Strasse 49a, D-50935 Cologne, Germany

[1] We present tools for rapid and quantitative detection of sediment lamination. The BMPix tool extracts color and gray scale curves from images at pixel resolution. The PEAK tool uses the gray scale curve and performs, for the first time, fully automated counting of laminae based on three methods. The maximum count algorithm counts every bright peak of a couplet of two laminae (annual resolution) in a smoothed curve. The zero-crossing algorithm counts every positive and negative halfway passage of the curve through a wide moving average, separating the record into bright and dark intervals (seasonal resolution). The same is true for the frequency truncation method, which uses Fourier transformation to decompose the curve into its frequency components before counting positive and negative passages. The algorithms are available at doi:10.1594/PANGAEA.729700. We applied the new methods successfully to tree rings, to well-dated and already manually counted marine varves from Saanich Inlet, and to marine laminae from the Antarctic continental margin. In combination with $\mathrm{AMS}^{14} \mathrm{C}$ dating, we found convincing evidence that laminations in Weddell Sea sites represent varves, deposited continuously over several millennia during the last glacial maximum. The new tools offer several advantages over previous methods. The counting procedures are based on a moving average generated from gray scale curves instead of manual counting. 
Hence, results are highly objective and rely on reproducible mathematical criteria. Also, the PEAK tool measures the thickness of each year or season. Since all information required is displayed graphically, interactive optimization of the counting algorithms can be achieved quickly and conveniently.

Components: 8801 words, 9 figures, 3 tables.

Keywords: laminations; varves; geochronology; paleoclimatology; marine geology; tree rings.

Index Terms: 0473 Biogeosciences: Paleoclimatology and paleoceanography (3344); 1199 Geochronology: General or miscellaneous (4260); 3225 Mathematical Geophysics: Numerical approximations and analysis (4260).

Received 8 May 2009; Revised 3 December 2009; Accepted 30 December 2009; Published 19 March 2010.

Weber, M. E., L. Reichelt, G. Kuhn, M. Pfeiffer, B. Korff, J. Thurow, and W. Ricken (2010), BMPix and PEAK tools: New methods for automated laminae recognition and counting-Application to glacial varves from Antarctic marine sediment, Geochem. Geophys. Geosyst., 11, Q0AA05, doi:10.1029/2009GC002611.

Theme: EarthTime: Advances in Geochronological Technique

Guest Editors: D. Condon, G. Gehrels, M. Heizler, and F. Hilgen

\section{Introduction and Rationale}

[2] The starting point to write this paper was the abundant millimeter-scale lamination of alternating bright and dark layers we found in sediment cores from the continental slope of the southeastern Weddell Sea. Naturally, we were interested in whether couplets of two laminae represent true varves, i.e., the deposition of one year, and could hence be used as a high-resolution chronology as well as a seasonal to longer-term record of climate variability. Annually laminated archives are recognized as very high-resolution records of environmental change [e.g., Hughen et al., 2004a], providing absolute and floating chronologies over centuries to millennia. They are important paleoclimate indicators in a number of archives, e.g., marine and lacustrine sediment, tree rings, ice cores, and corals [e.g., Kemp, 1996]. A seasonal- to decadal-scale insight into Antarctic ice sheet and bottom water dynamics for instance, would allow addressing a number of important scientific questions such as the presence of sunspot cycles and the extent of glacial bottom water production.

[3] Surprisingly, we had to learn that, so far, no tools are available for comprehensive and automated laminae investigation, although there are important archives available for chronostratigraphic and paleoclimatic studies. Therefore, we developed tools to (1) retrieve sediment optical and physical data at submillimeter resolution, (2) count laminae quantitatively, and (3) measure their thicknesses. Accordingly, the focus of this paper is the description of the new tools, the evaluation of their strengths and weaknesses, and the application to the laminated sites from the Weddell Sea, with reference tests to laminated sections of Saanich Inlet [Nederbragt and Thurow, 2001b] and tree rings.

[4] Antarctica is becoming increasingly interesting, because the Southern Ocean may have acted as a major supplier of deep water (Antarctic Bottom Water, AABW) during stadials, when production of North Atlantic Deep Water (NADW) was sluggish or even terminated [e.g., Stocker and Johnsen, 2003; Knutti et al., 2004]. Unfortunately, there is a lack of high-resolution Antarctic sediment cores that could provide detailed and continuous insight into Antarctic climate variability during the last glacial. To fill in that gap, we reexamined $\mathrm{AMS}^{14} \mathrm{C}$ dated sediment sites from the southeastern Weddell Sea (Figure 1). Those sites are located on sediment ridges of the Antarctic continental margin and contain ultrahigh-resolution records of glacial ice sheet dynamics and bottom water production [Kuhn and Weber, 1993; Melles and Kuhn, 1993; Weber et al., 1994; Michels et al., 2002].

\section{Data}

[5] We used piston and gravity cores retrieved in the late 1980 s to early 1990 s with R/V Polarstern on the continental slope of the southeastern and southern Weddell Sea (Figure 1 and Table 1). Previous work has focused on sedimentology, 


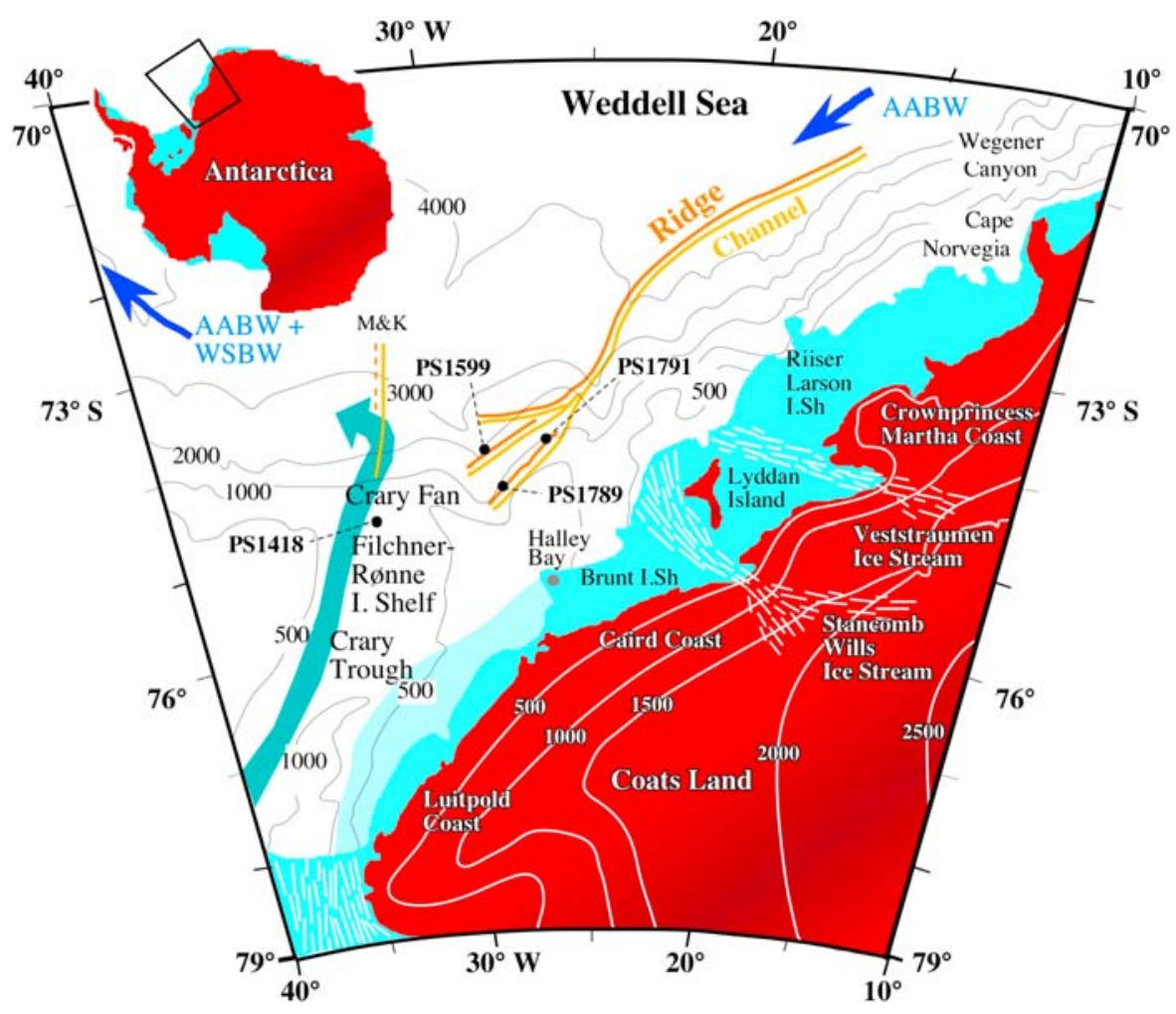

Figure 1. Map of the southeastern Weddell Sea (depth contours modified from Gebco [1983]). Sediment sites (bold PS numbers) are located on southwest northeast running ridges (orange) on the continental slope. The ridges are accompanied by channels on their southeastern side. Flow directions (arrows) of selected water masses (blue) of the Weddell Gyre counter the channel-ridge systems (AABW, Antarctic Bottom Water; WSBW, Weddell Sea Bottom Water). Thickness of the East Antarctic Ice Sheet is indicated by white numbers. M\&K, channel-ridge system investigated by Melles and Kuhn [1993].

geochemistry, and age determination (using accelerator mass spectrometry, $\mathrm{AMS}^{14} \mathrm{C}$ ). Kuhn and Weber [1993] and Weber et al. [1994] studied Sites PS1599, PS1789. Novel sediment parameters have now been obtained from Site PS1791. Also, we incorporated data from ODP Leg 169S [Nederbragt and Thurow, 2001b], Sites 1033 and 1034 from Saanich Inlet.

[6] We generated ultrahigh-resolution (centimeters to submillimeters) paleoclimate proxy records, primarily from nondestructive core logging techniques that have not been available in the early 1990s. Line scan photographs were taken with a camera system attached to an Avaatech XRF core scanner at pixel resolution (i.e., roughly 12,000 measurements per $\mathrm{m}$ ). Specifically X-radiographs were important for the scope of this paper. We took $25 \mathrm{~cm}$ long plastic plates and exposed them for 3 to 5 min using a HP 43855 X-Ray System. The resulting negatives were then scanned at $300 \mathrm{dpi}$ and analyzed with the tools described below.
[7] For individual $\mathrm{AMS}^{14} \mathrm{C}$ dating, we collected carbonate shell material from up to 2000 wellpreserved foraminifera (up to $50 \mathrm{mg}$ ) of the species Neogloboquadrina pachyderma (sinistral) in a narrow size range $(125-375 \mu \mathrm{m})$ if possible. Samples were pretreated with $\mathrm{H}_{2} \mathrm{O}_{2}$ to remove organic compounds. Measurements were conducted at the ETH Zürich (for detail, see Weber et al. [1994]).

\section{BMPix and PEAK Tools}

[8] Existing numerical tools for laminae investigation do not combine laminae recognition and

Table 1. Core Locations Used in This Study

\begin{tabular}{lclll}
\hline Station & $\begin{array}{c}\text { Core } \\
\text { Length }\end{array}$ & Latitude & Longitude & $\begin{array}{c}\text { Water } \\
\text { Depth }\end{array}$ \\
\hline PS1599 & $11.32 \mathrm{~m}$ & $74^{\circ} 04^{\prime} \mathrm{S}$ & $27^{\circ} 42^{\prime} \mathrm{W}$ & $2487 \mathrm{~m}$ \\
PS1789 & $14.19 \mathrm{~m}$ & $74^{\circ} 15^{\prime} \mathrm{S}$ & $27^{\circ} 18^{\prime} \mathrm{W}$ & $2411 \mathrm{~m}$ \\
PS1791 & $12.89 \mathrm{~m}$ & $7^{\circ} 54^{\prime} \mathrm{S}$ & $26^{\circ} 32^{\prime} \mathrm{W}$ & $2894 \mathrm{~m}$ \\
ODP Site 1033C & $72.70 \mathrm{~m}$ & $48^{\circ} 35^{\prime} \mathrm{N}$ & $123^{\circ} 20^{\prime} \mathrm{W}$ & $226 \mathrm{~m}$ \\
ODP Site 1034C & $103.00 \mathrm{~m}$ & $48^{\circ} 38^{\prime} \mathrm{N}$ & $123^{\circ} 30^{\prime} \mathrm{W}$ & $201 \mathrm{~m}$ \\
\hline
\end{tabular}




\section{BMPix Tool}
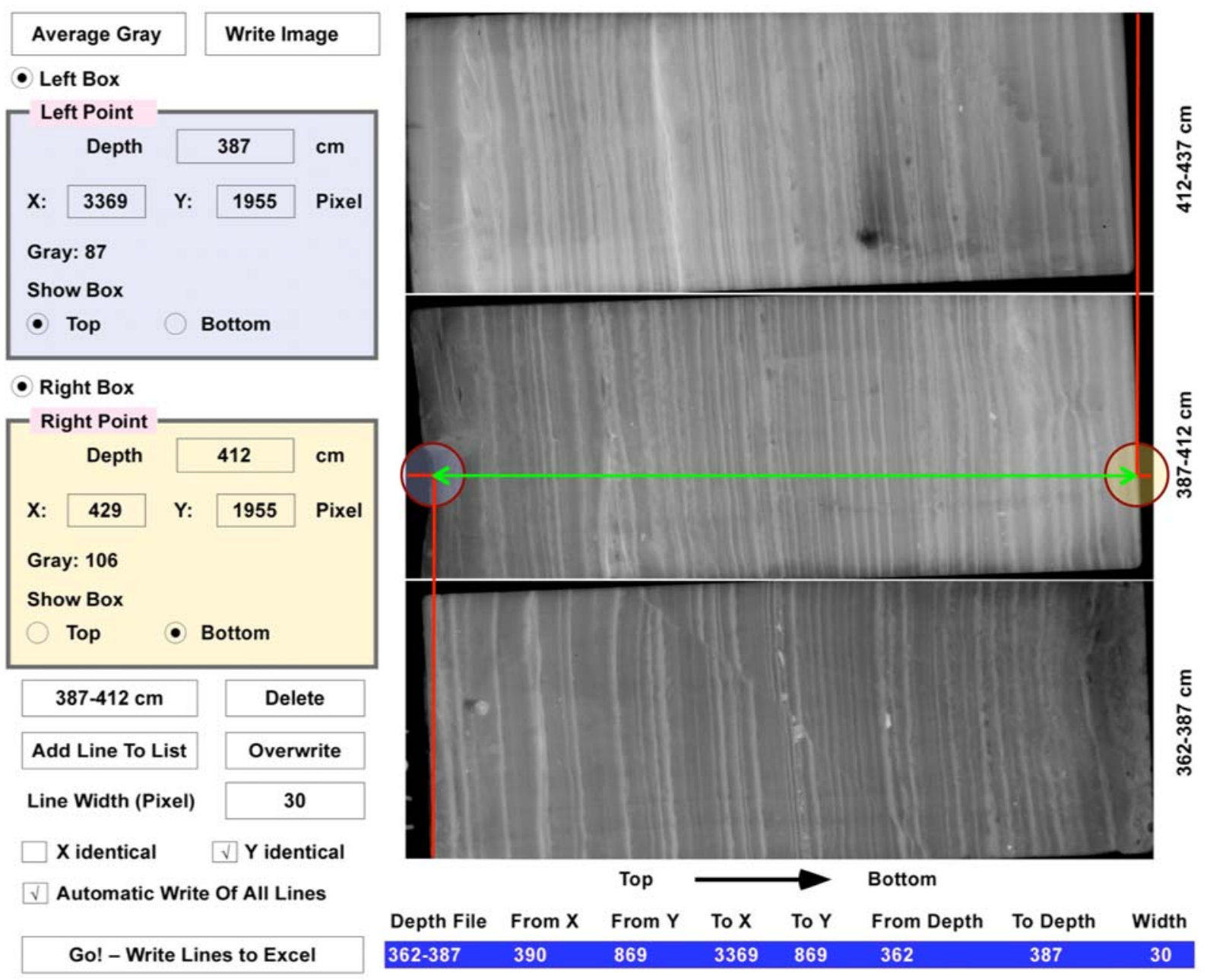

Figure 2. Input mask of the BMPix tool. RGB and gray scale data are generated at pixel resolution along a green profile line between predefined start (blue box) and end (yellow box) points for any given BMP image. Here 2940 data points (pixels 429-3369) were measured over a $25 \mathrm{~cm}$ long X-radiograph image (387-412 cm); that is, resolution is 12 measurements $/ \mathrm{mm}$ or $85 \mu \mathrm{m}$. White numbers in list at bottom right contain reference data from previous profile line in section 362-387 cm. Upon completion, gray scale data will be extracted from all profile lines added to list.

counting [e.g., Schaaf and Thurow, 1994]; some are platform-specific (NIH-Image [see Nederbragt and Thurow, 2001a]), provide only limited control over the scanning process (ImageJ [see Boes et al., 2005]), or may be more suited for tree rings [e.g., RinnTech, 2002] or thin sections [Zolitschka, 1996]. Therefore, we developed a number of Excel-based macros to extract ultrahigh-resolution (submillimeter scale) paleoclimate proxy data, count layers quantitatively, associate counts with depths in core, and process the huge amount of data. The basic concept was laid out by Reichelt [2007]. The software tools are available as auxiliary material. ${ }^{1}$ The software and all future updates thereof are also available at doi:10.1594/PANGAEA.729700. It was crucial to develop tools that are straightforward, highly interactive and that provide immediate visual control of the detection and counting process.

\subsection{BMPix Tool}

[9] The macro linearly extracts red, green, blue $(\mathrm{R} / \mathrm{G} / \mathrm{B})$, and gray values at pixel resolution along a

\footnotetext{
${ }^{1}$ Auxiliary materials are available in the HTML. doi:10.1029/ 2009GC002611.
} 


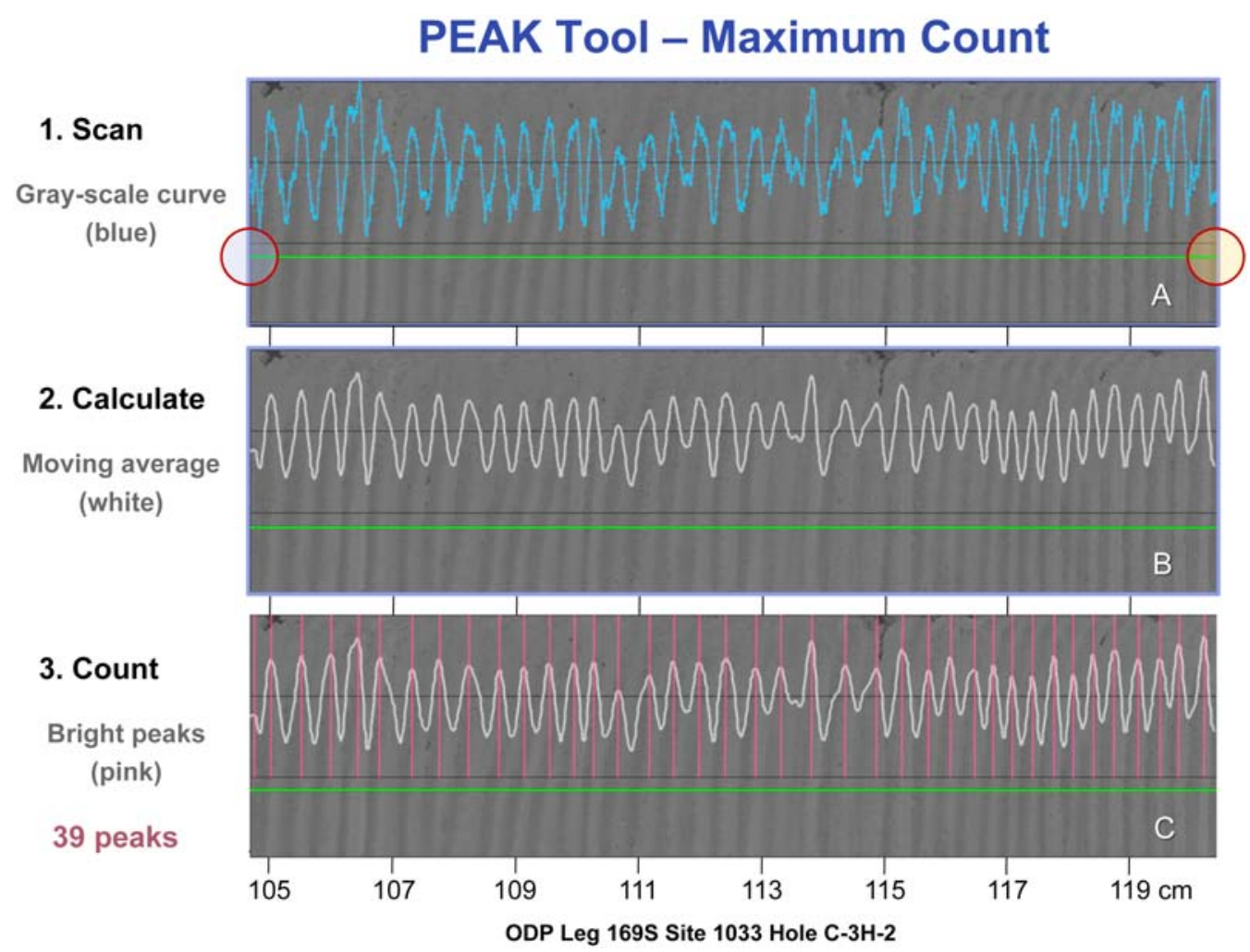

Figure 3. Work flow for maximum count algorithm of PEAK tool for automated layer counting. (a) Gray scale curve (light blue) is first generated along green line by BMPix tool between predefined start and end points (circles). Analysis was conducted on ODP Leg 169S Site 1033 from Saanich Inlet (see underlying image [Nederbragt and Thurow, 2001b]). (b) Narrow moving average (white) is then calculated from gray scale curve. (c) Count of every maximum (bright layer) from average (pink vertical bars). Accordingly, 39 peaks were counted over $15 \mathrm{~cm}$.

profile line between freely adjustable start and end points (circles in Figure 2) from any given BMP image file. This means that color and gray values can be generated from surface images (e.g., photos, line scan images) and from transmitted light images (e.g., X-radiographs, thin sections). For the Antarctic sites for instance, we scanned radiograph images at 300 dpi. A comparable resolution was available for the photos from the Saanich Inlet sites. This translates into approximately 12 measurements $/ \mathrm{mm}$, or, in other words, the resolution is roughly $85 \mu \mathrm{m}$ (see also Figure 2).

[10] The number of pixel (line width) over which the measurement is averaged can be adjusted to reduce noise and the pixel position is converted to a depth scale. Also, instead of using a single profile line covering the entire image, multiple lines can be used and shifted laterally if required. Furthermore, the profile line(s) are, if requested, stored along with the image for later reevaluation or readjustment of settings. An example for a gray scale curve that has been generated is given in Figure 3a for a sediment section from ODP Leg 169S from Saanich
Inlet [Nederbragt and Thurow, 2001b]. This first step produces high volumes of data, which are kept in individual work sheets of an Excel workbook. Additional macros collect, condense, or export the data if required. The BMPix tool provides the data necessary for the subsequent analysis with the PEAK tool.

\subsection{PEAK Tool}

[11] This macro counts the overall amount of sediment layers from gray scale curves that have been generated with the BMPix tool. We implemented three different approaches, each of which comprises strengths and weaknesses (see discussion later): (1) the maximum count method, (2) the zero crossing method, and (3) the frequency truncation method.

[12] The basic idea of the maximum count method is that every cycle of a dark and a bright sediment layer corresponds to a local maximum in the brightness curve that is generated as a first step (given in light blue in Figure 3a). In a second step, 


\section{PEAK Tools}
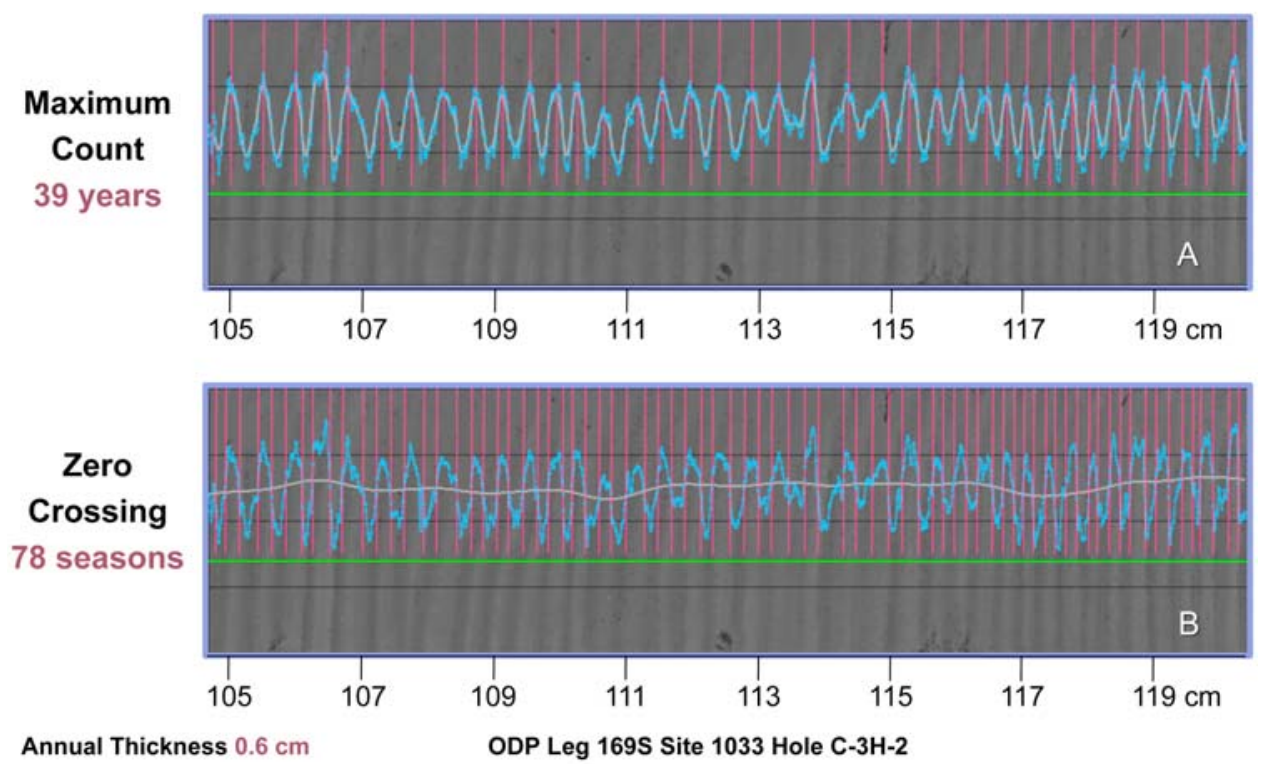

Figure 4. The two main algorithms of the PEAK tool for automated layer counting. (a) Combination of the three steps employed for maximum count algorithm shown in Figure 3. Accordingly, all information necessary for quantitative evaluation is displayed on top of each other: underlying image, profile line (green) along which gray scale curve (light blue) is generated, and narrow moving average (gray). Analysis was conducted on varved records from Saanich Inlet (ODP Leg 169S Site 1033 [Nederbragt and Thurow, 2001b]). (b) Zero-crossing algorithm calculates wide and adjustable moving average (gray) and counts all positive and negative passages of the gray curve (light blue) through the average. Thus, record is divided into bright and dark intervals, i.e., 78 seasons.

we applied smoothing to eliminate high-frequency noise created by natural fluctuations and/or image processing (gray curve in Figure 3b). In a third step the algorithm identifies the local maxima of the smoothed curve and counts them (given as pink vertical lines in Figure 3c). Accordingly, there is one count for every bright layer (39 counts in total), i.e., one count for every couplet. The result is plotted directly on the original image to enable the user to readjust the three parameters defining the rules that have to be fulfilled in order to count as a maximum: the full width half maximum (FWHM) of the Gaussian smoothing, the minimum cycle length, and the minimum amplitude.

[13] Figure 4a combines the three parts of Figure 3 and displays the gray scale curve (light blue), the narrow moving average (gray), the maxima counts (pink), the profile line (green), and the underlying image on which the analysis is conducted. Since the sites from Saanich Inlet are known to be varves (see also later discussion), the 39 peaks translate into 39 years of deposition.

[14] The zero-crossing method (Figure 4b) detects the transition between a bright and a dark layer by determining the point where the brightness curve crosses its average value. The average is calculated with a FWHM larger than the cycle length, which also accounts for potential overall brightness trends across longer core sections. Also here, the FWHM, the minimum cycle length, and the minimum amplitude can be adjusted. A count is given for every crossing point with changing signs, i.e., when layer thickness and the deviation of its brightness compared to the average exceeds minimum values.

[15] For varved sites with couplets (such as Saanich Inlet), the zero-crossing method divides the seasons. Accordingly, there are 78 seasonal counts in Figure $4 \mathrm{~b}$ at alternating positions relative to the maximum count method (Figure $4 \mathrm{a}$ ).

[16] In order to show that the PEAK tools can also be applied to tree rings, we added a dendrochronological example in Figure 5. Here, individual layers are relatively thick and hence easy to identify. The maximum count method (Figure 5a) counts 27 cycles (dashed black lines), i.e., 27 years of growth. The zero-crossing method detects 54 seasonal layers (Figure 5b). All automated counts were confirmed by manual counts.

[17] The tree ring example also displays the frequency truncation method (Figure 5c), which uses 


\section{PEAK to ol}

Maximum count

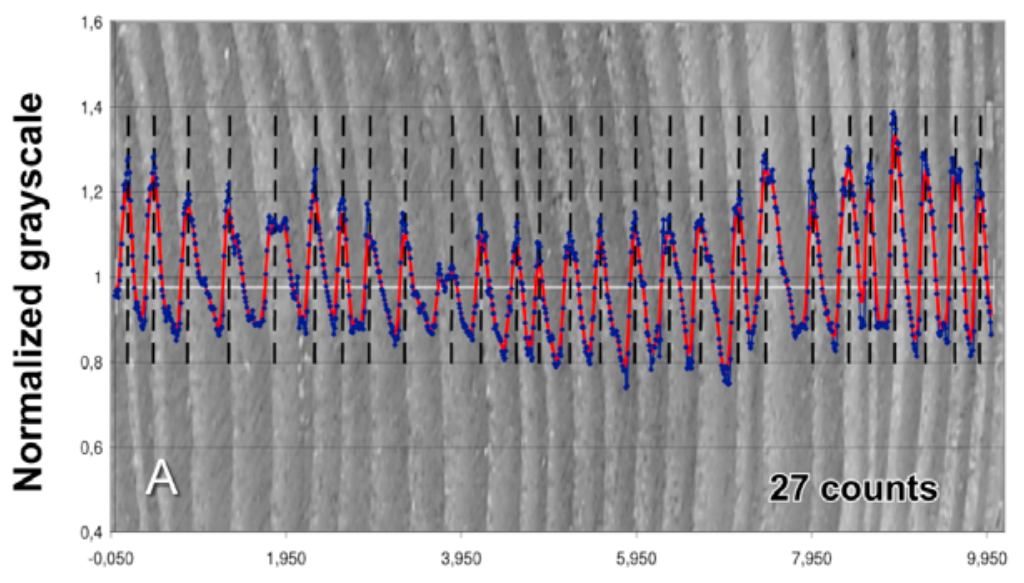

Zero crossing

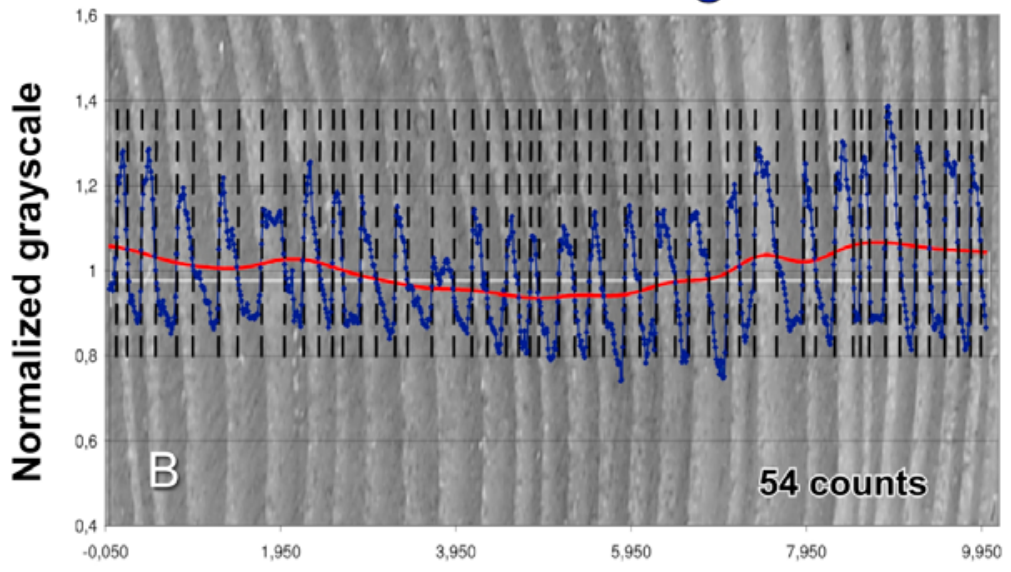

Frequency truncation

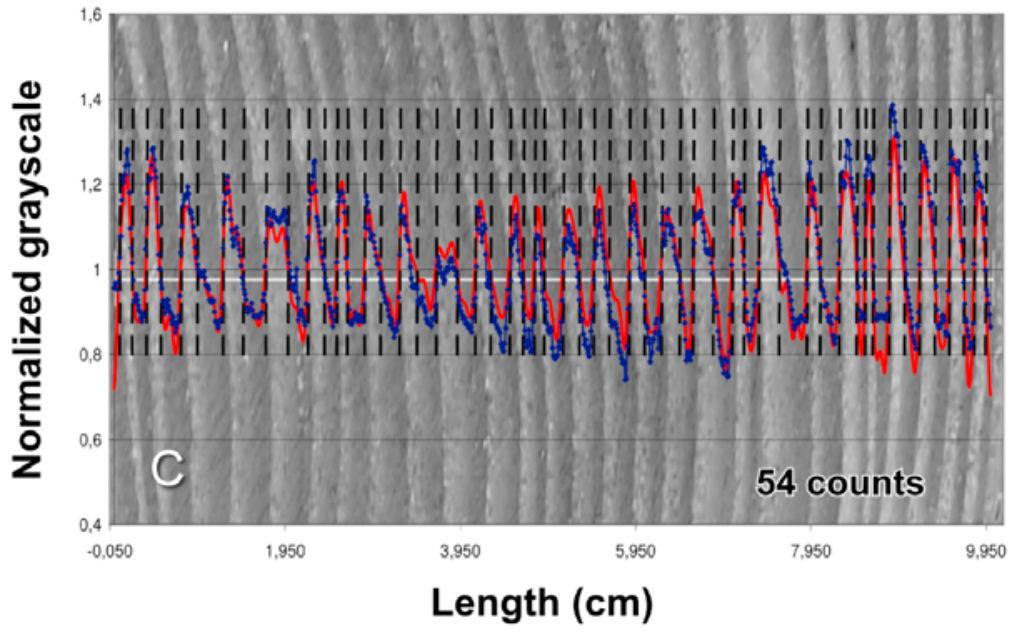

Figure 5. PEAK tool algorithms for automated layer counting applied to tree rings. (a) Maximum count method showing gray scale curve (blue) generated with BMPix tool, narrow moving average (red), and counts (black dashed lines) with 27 years of growth. (b) Zero crossing method with wide moving average (red) and 54 seasonal counts. (c) Frequency truncation method with Fourier transformed gray scale curve (red), also with 54 seasonal counts. 


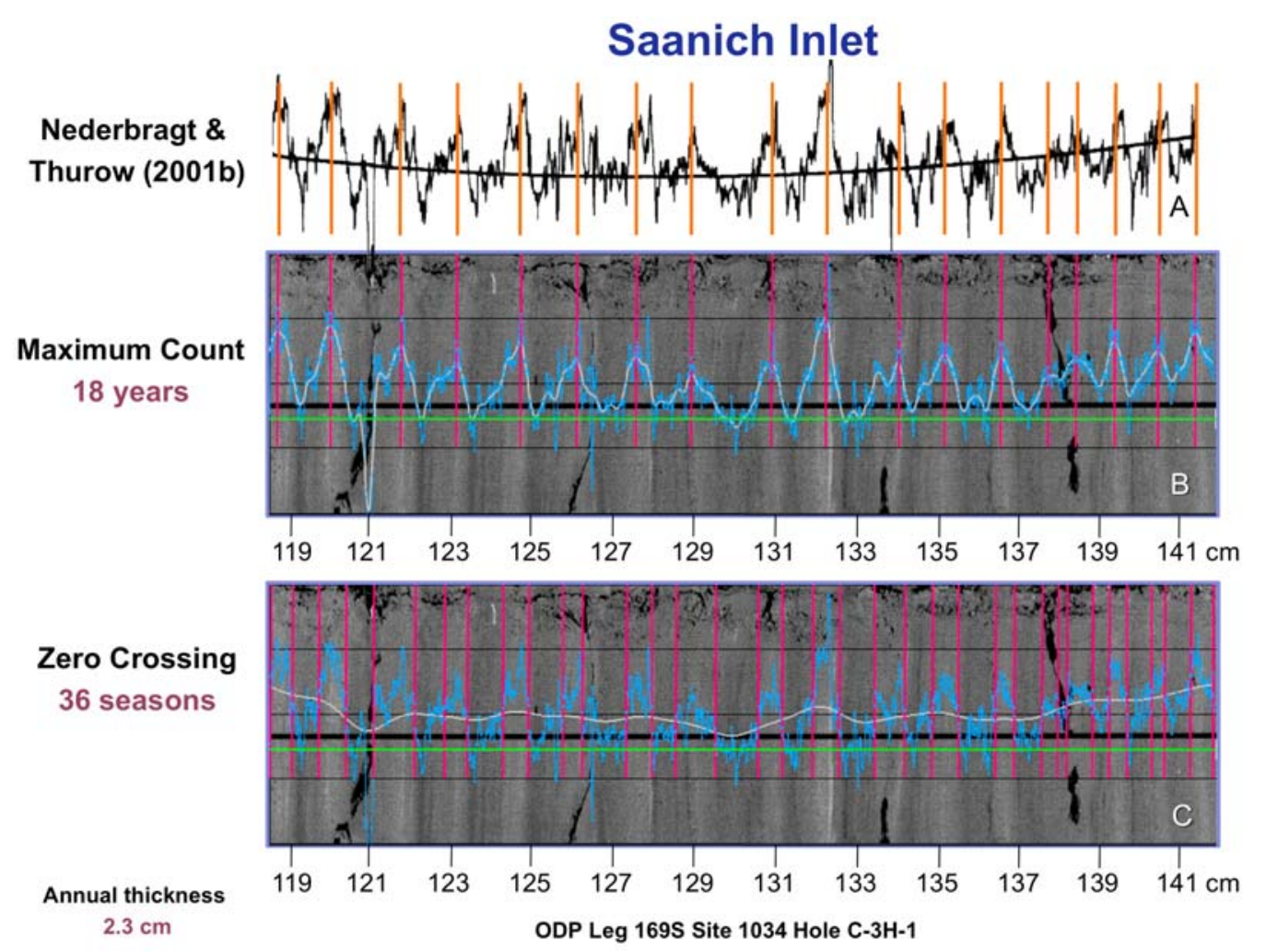

Figure 6. Comparison of gray scale generation and layer counting for ODP Leg 169S Site 1034. (a) Gray scale curve generated by Nederbragt and Thurow [2001b]. (b) Gray scale curve (light blue) generated with BMPix tool. Note that even small-scale features are resembled. Also, manual counts (orange) from Nederbragt and Thurow [2001b] agree with automated counts (pink) from maximum count algorithm of PEAK tool (18 years of record). (c) Thirty-six seasonal counts provided by the zero-crossing algorithm.

Fourier transformation to decompose the oscillating curve into its frequency components. After subtraction of low-frequency shifts and high-frequency noise, counting of the zero crossings is performed (54 seasonal layers in total). The user-defined parameters of this method are lower and upper cutoff frequencies, minimum layer thickness, and minimum amplitude.

[18] Since all three counting algorithms associate the position of a count with a specific pixel (depth in profile), PEAK also measures the thickness of every year (maximum count) or every season (zero crossing and frequency truncation). Therefore, essential data for successive time series analysis is collected as well.

\section{Evaluating the BMPix and PEAK Tools: Saanich Inlet}

[19] After the initial tests on tree rings (see Figure 5), we tested the new methods more thoroughly on well-known and well-dated laminated marine sed- iment sequences. We chose Sites 1033 and 1034 of ODP Leg 169S from Saanich Inlet, British Columbia. These sites provide laminated Holocene sediments from an anoxic fjord on the coastline of Vancouver Island. Laminae alterations describe true varves and consist of diatom-rich and diatompoor clays and silts that represent the last 6000 years of regional climate according to ${ }^{14} \mathrm{C}$ dating of Bornhold et al. [1998]. Occasionally, massive layers interrupt the varved sequences. The sequences have been scanned for gray scale and counted manually for layers by Nederbragt and Thurow [2001b] using photographs (see underlying images in Figures 3, 4, and 6).

[20] First, we put to the test the BMPix tool by rescanning the core photographs. An example is shown for core section 1034C-3H-1 (Figure 6), a section that has already been displayed by Nederbragt and Thurow [2001b, Figure 2]. Our scanning line (green) was just underneath their line (black) to achieve the closest reproduction possible. Both gray scale curves (the blue curve generated 
Table 2. Varve Counting Results for ODP Leg 169S Site 1033C Holes 1033C-3H1 to 1033C-3H4 Between Massive Layers 19 and $23^{\mathrm{a}}$

\begin{tabular}{cccc}
\hline $\begin{array}{c}\text { Interval (Between } \\
\text { Massive Layers) }\end{array}$ & $\begin{array}{c}\text { Counts by Nederbragt and } \\
\text { Thurow }[2001 \mathrm{~b}]\end{array}$ & $\begin{array}{c}\text { Counts } \\
\text { (This Paper) }\end{array}$ & Discrepancy \\
\hline ML19/20 & 396 years & 412 years & 16 years $(3.9 \%)$ \\
ML20/21 & 127 years & 127 years & 0 years $(0.0 \%)$ \\
ML21/22 & 203 years & 205 years & 2 years $(1.0 \%)$ \\
ML22/23 & 139 years & 141 years & 2 years $(1.4 \%)$ \\
\hline
\end{tabular}

${ }^{\mathrm{a}}$ See also Nederbragt and Thurow [2001b, Tables 1 and 2]. ML, massive layer.

with the BMPix tool, and the black curve generated by Nederbragt and Thurow [2001b]) are virtually identical, even small-scale features reproduce very well (Figures 6a and 6b).

[21] Then, we used the PEAK tools to count the varves and to compare the results to Nederbragt and Thurow [2001b]. Figure 6 shows that the automated counts provided by the maximum count algorithm (pink) are in agreement with the manual counts (orange). All varves are identified and represent 18 years of deposition. Figure $6 \mathrm{c}$ shows the zero-crossing algorithm of PEAK. It also identifies all varves and, in addition, it separates the dark from the bright sections, thereby allowing for the distinguishing of two seasonal signals (36 seasons in total). We wish to point out that the agreement between the maximum count and the zero-crossing methods given in Figures 4-6 is, although highly desired, not obvious because both methods rely on entirely different algorithms.

[22] Finally, we compared count results over four longer intervals that contain continuous varves and that are separated by massive layers (ML; for a detailed description of the sections see Nederbragt and Thurow [2001b, Tables 1 and 2]). The results are displayed in Table 2. As for the settings of the maximum count algorithm of PEAK, a good starting point for the number of pixel over which the average should be calculated was approximately half the number of pixel that was anticipated for the average width of a bright lamina. A minimum width of only a few pixel for the moving average was an adequate setting to count peaks for very fine-scale lamination $(\leq 0.6 \mathrm{~mm})$. However, when laminae become thicker ( $\geq 1 \mathrm{~cm}$ (see Figure 6)), enhanced internal variability may occur within broader peaks. In these cases, the minimum width was increased in order to avoid counting internal peaks as laminae.

[23] As a result, the amount of varves counted by PEAK between ML 20/21, 21/22, and 22/23 is almost identical (473 compared to 469 varves).
Only between ML 19 and 20, there is a slight discrepancy of 16 varves (412 compared to 396 (Table 2)). The difference here may be more a matter of opinion than one of methodology. On the other hand, only PEAK visualizes the counting results and therefore, errors can be recognized and corrected for. In summary, there is a good agreement between manual and automated counting for Saanich Inlet.

[24] The advantage of the PEAK tool over manual counting is its interactivity and visualization capability. Each time a setting is changed and the macro is executed, the results will immediately be visualized. Accordingly, the underlying image will be displayed along with the profile line for the gray scan (green lines in Figures 2-4), the blue curve represents the gray scale curve generated along the green line, the gray line displays the moving average calculated from the gray scale curve, and the pink lines indicate the positions of the individual counts that were calculated from the average. Accordingly, all information necessary for quantitative laminae evaluation are displayed on top of each other. Iterative optimization can therefore be achieved quickly and conveniently. Bearing this in mind, we investigated the sediments from the Antarctic continental margin.

\section{Sediment Ridges in the Southeastern Weddell Sea, Antarctica}

[25] At the continental margin of the southeastern Weddell Sea, there are several, up to $300 \mathrm{~m}$ high and up to $100 \mathrm{~km}$ long sediment ridges with channels on their eastern sides (orange and yellow lines in Figure 1). They are located northeast [Kuhn and Weber, 1993] of the Crary Fan. The shelf ice edge oscillated during the Quaternary climatic cycles. At least during the sea level low stand of the last glacial maximum (LGM), the continental ice sheet grounded on the seafloor and had advanced to the shelf break [Elverhøi, 1981; Stuiver et al., 1981]. 
Table 3. $\mathrm{AMS}^{14} \mathrm{C}$ Determinations on Carbonate Shells of Planktonic Foraminifera Neogloboquadrina pachyderma (sinistral) From Sites PS1599 and PS1789 and Corrections Applied to the Data ${ }^{\mathrm{a}}$

\begin{tabular}{|c|c|c|c|c|c|c|}
\hline Station & PS1599 & PS1599 & PS1599 & PS1789 & PS1789 & PS1791 \\
\hline AMS sample ID & A & B & $\mathrm{C}$ & D & $\mathrm{E}$ & \\
\hline Core depth $(\mathrm{cm})$ & 378 & 564 & 928 & 199 & 1,211 & \\
\hline Age ${ }^{14} \mathrm{C}$ (years B.P.) & $19,210 \pm 210$ & $20,700 \pm 160$ & $22,150 \pm 230$ & $17,300 \pm 140$ & $19,990 \pm 250$ & \\
\hline $\begin{array}{l}\text { Age }{ }^{14} \mathrm{C} \text { reservoir } \\
\text { corrected (years B.P.) }\end{array}$ & $17,995 \pm 212$ & $19,485 \pm 163$ & $20,935 \pm 232$ & $16,085 \pm 143$ & $18,775 \pm 252$ & \\
\hline $\begin{array}{l}\text { Age CalPal } \\
\text { (cal years B.P.) }\end{array}$ & $21,675 \pm 456$ & $23,282 \pm 354$ & $25,077 \pm 446$ & $19,223 \pm 259$ & $22,476 \pm 461$ & \\
\hline Age difference (years) & A-B: 1,607 & B-C: 1,795 & A-C: 3,402 & D-E: 3,253 & & \\
\hline Error propagation (years) & A-B: \pm 577 & B-C: \pm 569 & A-C: \pm 638 & D-E: \pm 529 & & \\
\hline $\begin{array}{l}\text { LGM sedimentation } \\
\text { rate }(\mathrm{cm} / \mathrm{kyr})\end{array}$ & & & A-C: 162 & D-E: 311 & & $350 ?$ \\
\hline $\begin{array}{l}\text { Average varve } \\
\text { thickness (mm) }\end{array}$ & & & 3.0 & 3.1 & & 3.5 \\
\hline $\begin{array}{l}\text { Laminae count } \\
\text { (maximum) }\end{array}$ & total: 2,912 & & A-C: 1,634 & D-E: 3,329 & total: 4,029 & total: 3,002 \\
\hline $\begin{array}{l}\text { Laminae count } \\
\quad \text { (zero crossings) }\end{array}$ & & & & & & total: 6,000 \\
\hline
\end{tabular}

${ }^{a}$ Reservoir corrections (1,215 \pm 30 years) are based on living bryozoa from neighboring Site PS1418-1 [see Melles, 1991]. Calendar ages were calculated using CalPal ${ }^{\text {online }}$ (U. Danzeglocke et al., CalPal-2007online, http://www.calpal-online.de/, accessed 28 February 2009). Error propagation and sedimentation rates are given for specific intervals.

Thus, the encapsulated basal detritus was delivered directly to the continental slope by sediment gravitational processes [e.g., Wright et al., 1983; Anderson et al., 1986].

[26] In front of the ice sheet, an extensive coastal polynia may have injected high-salinity bottom currents that reworked and modified the sediments on the continental slope [Weber et al., 1994]. The thermohaline currents as well as turbidity currents were canalized toward the northeast and sediment ridges formed on their northwestern sides as levees due to Coriolis Force, a process that is supported by contour currents flowing parallel to the continental slope in southwestern direction, thereby opposing the density currents [Michels et al., 2002]. In addition, detrital material was supplied by iceberg drift from the northeast. Due to extensive sea ice coverage, the glaciomarine sediments of the Antarctic continental margin contain predominantly terrigenous material and only small amounts of biogenic components [Elverhøi, 1984; Fütterer et al., 1988; Fütterer and Melles, 1990]. The lack of biogenic carbonate is a major handicap for dating and the development of a sound stratigraphic concept.

\section{6. $A M S^{14} \mathrm{C}$ Dating and Reservoir Effect in Antarctic Sediment}

[27] To evaluate whether or not the Weddell Sea laminae represent true varves requires a thorough examination of the available age information. The sediment ridges from the southeastern Weddell Sea reveal extremely high sedimentation rates $(1.6-3.5 \mathrm{~m} / \mathrm{ka}$ (Table 3)) during the LGM as deduced from $\mathrm{AMS}^{14} \mathrm{C}$ data for Sites PS1599 and PS1789 [see also Weber et al., 1994].

[28] Oceanic waters contain $\mathrm{CO}_{2}$ out of equilibrium with the atmosphere, on account of the long residence time of carbon dioxide in the deep ocean. This marine reservoir effect is only a few centuries in low latitudes. For Antarctic marine carbonates however, it is $1200-1300{ }^{14} \mathrm{C}$ years B.P. [Gordon and Harkness, 1992; Berkman and Forman, 1996], an age range that has been found by independent ${ }^{226} \mathrm{Ra} / \mathrm{Ba}$ dating [Staubwasser et al., 2004]. For organic matter it may exceed several millennia due to reworked carbon (see discussion by Domack et al. [1999]). Therefore, we used cleaned marine carbonates (monospecific planktonic foraminifera shells of Neogloboquadrina pachyderma, picked in a narrow size range). We were fortunate enough to be able to use $\mathrm{AMS}^{14} \mathrm{C}$ dated carbonate shells of living bryozoa from neighboring Site PS1418-1 [see Melles, 1991] from the upper continental slope. Accordingly, we applied a correction of $-1215 \pm 30$ years.

[29] Then we corrected these ages using the $\mathrm{CalPa}^{\text {online }}$ tool (U. Danzeglocke et al., CalPal2007online, http://www.calpal-online.de/, accessed 28 February 2009), to convert ${ }^{14} \mathrm{C}$ ages to calen- 

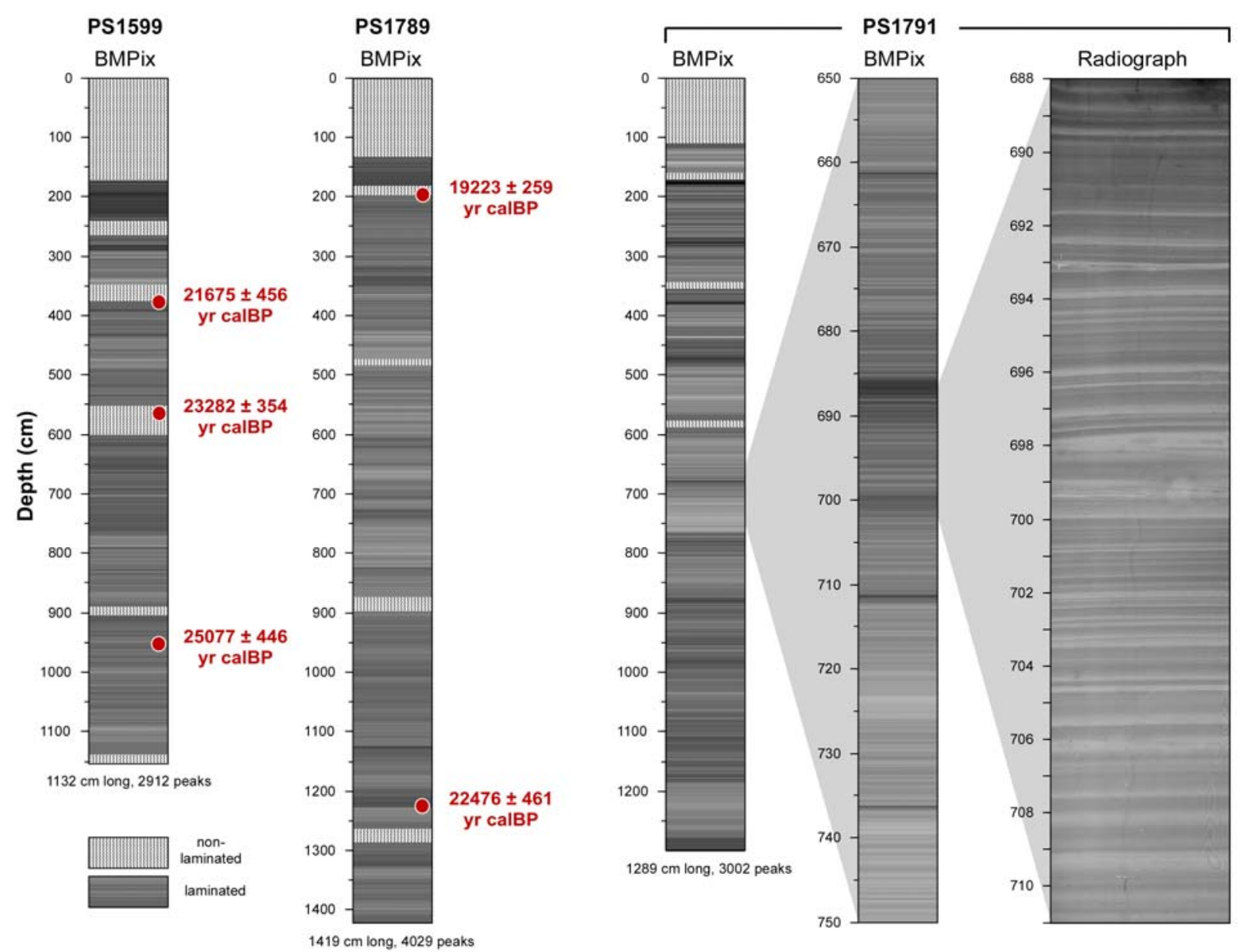

Figure 7. Facies and stratigraphy from three sediment sites (PS1599, PS178, and PS1791) located on sediment ridges in southeastern Weddell Sea. Textural plots originate from R/G/B data from X-radiographs, plotted with PanPlot (M. Diepenbroek et al., PanPlot, 2001, http://www.pangaea.de/Software/PanPlot). Dominant facies is lamination (see blow-up for Site PS1791), except for core top and few intercalated nonbioturbated intervals. Red numbers refer to $\mathrm{AMS}^{14} \mathrm{C}$ datings of marine carbonate shells from planktonic foraminifera Neogloboquadrina pachyderma.

drical ages. The software uses the radiocarbon calibration curve CalPal 2007 HULU, which correlates data from the Cariaco Basin [Hughen et al., 2006] to the Hulu speleothem record of Wang et al. [2001]. For the given time frame, comparison to INTCAL calibration curve Marine04 [Hughen et al., 2004b] revealed that CalPal ages are systematically older by 300 to 500 years for the LGM.

[30] The resulting ages from Sites PS1599 and PS1789 all belong to the LGM. We propagated the error in age determination (given as \pm in Table 3 ) through the different calibration steps by adding the square roots of the individual errors. This procedure was also used to calculate the error propagation for the duration of specific time slices.
Therefore, we are confident that the ages used in the discussion below are robust and reliable.

\section{BMPix and PEAK Tools Applied to Weddell Sea Laminated Sediment}

[31] Sediment material from the Antarctic continental margin is composed primarily of terrigenous components. For the LGM, high sedimentation rates (several $\mathrm{m} / \mathrm{ka}$ ) are documented for all sites investigated (see Table 3 ) and laminated mud is the dominant facies (see Figure 7). Occasionally, several $\mathrm{cm}$ thick bioturbated mud is intercalated. In addition, at the top 1-2 $\mathrm{m}$ of all sites, only bioturbated mud deposited at substantially lower sedimentation rates (only several $\mathrm{cm} / \mathrm{ka}$ ) on the ridges [Weber et al., 1994]. 


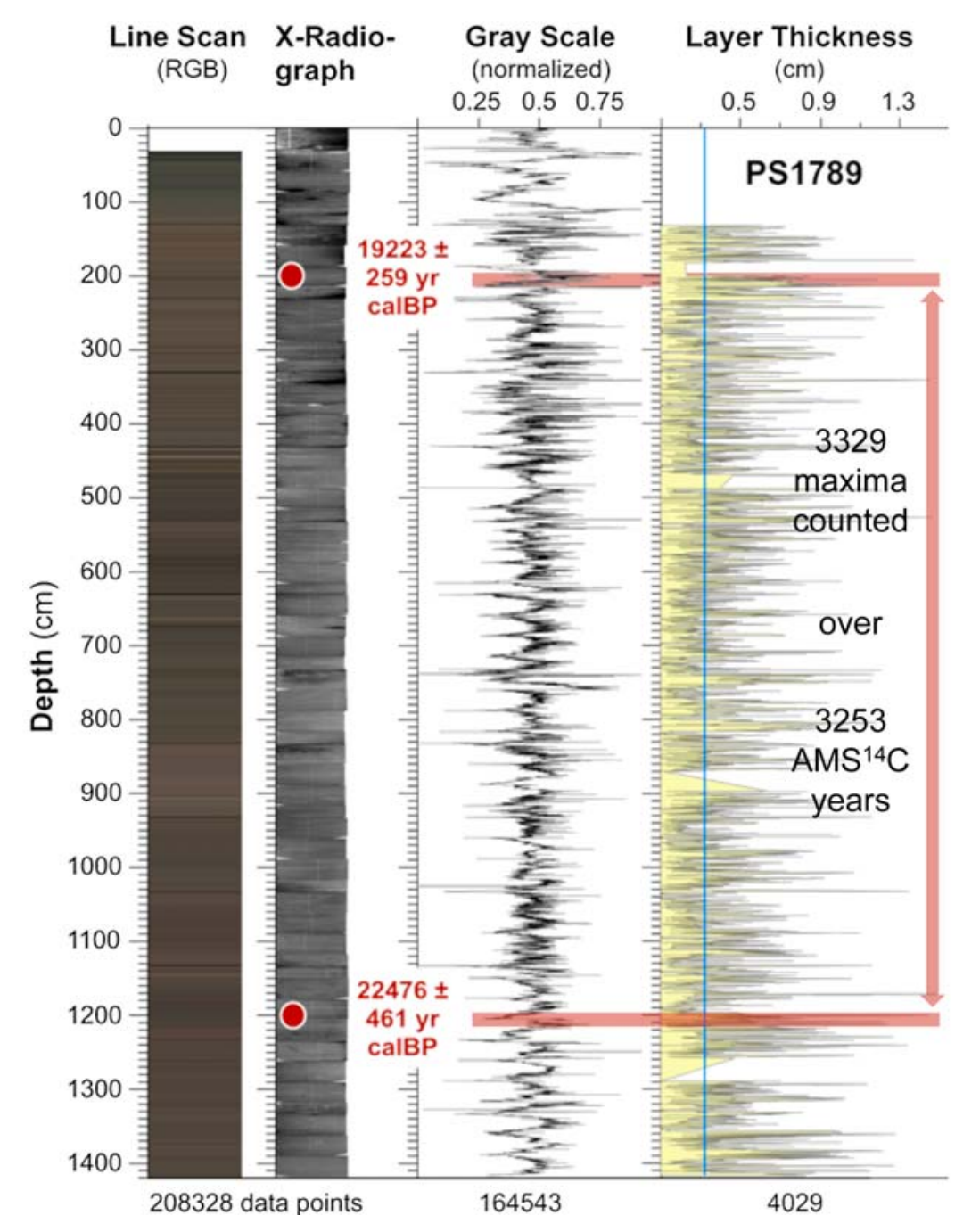

Figure 8. Selected nondestructive parameters determined on Site PS1789 from southeastern Weddell Sea. To the left are shown R/G/B data generated with line scan camera and plotted with PanPlot (M. Diepenbroek et al., PanPlot, 2001, http://www.pangaea.de/Software/PanPlot). Gray scale records were generated from X-radiographs using the BMPix tool. Layer thickness was determined with the maximum count algorithm of the PEAK tool and gives the thickness of a couplet. Blue line shows average thickness of $3.1 \mathrm{~mm}$ (see also Table 3). Numbers at the bottom give amount of data points generated; red numbers indicate AMS ${ }^{14} \mathrm{C}$ dates from Weber et al. [1994]. Note that 3329 maxima were counted over $3253( \pm 529) \mathrm{AMS}^{14} \mathrm{C}$ dated years during the LGM.

[32] The laminae from the southeastern Weddell Sea are rather complex in terms of thickness variability. Site PS1789 was first analyzed with the BMPix tool. For each $25 \mathrm{~cm}$ long X-radiograph image, we generated roughly 3200 data points for $\mathrm{R} / \mathrm{G} / \mathrm{B}$ color and gray scale along predefined profile lines. For the entire Site PS1789, we collected a total of 164,543 data points from X-radiographs. For comparison purposes, we also collected 208,328 gray scale data points from the line scan camera. In practice, the surface images provided by the line scan camera yield a less reliable documentation of the sediment structure and after initial tests, we concentrated on the transmitted-light images provided by the X-radiograph system.

[33] For data processing purposes, we designed additional macros to either export the high-volume data sets in full or to reduce (resample) them to desired depth (age) intervals, using interpolation. For example, to visualize lamination in Figure 7, we first reduced the data for each core to approximately 10,000 data points. Then, a macro merges the color data that was generated into a single column containing $\mathrm{R} / \mathrm{G} / \mathrm{B}$ data. This column was then plotted with PanPlot (M. Diepenbroek et al., PanPlot, 2001, http://www.pangaea.de/Software/ 
PanPlot) to illustrate textural variability (note that Figure 7 displays gray scales only because R/G/B data relies on gray scale $\mathrm{X}$-radiographs, whereas the $\mathrm{R} / \mathrm{G} / \mathrm{B}$ data in Figure 8 display colors because they relies on colored line scan images).

[34] The best and most reliable results for gray scale scanning were obtained by using a line width of 20-30 pixel. This is the amount of pixel parallel to stratification over which the value is integrated, in this case $1.5-2.5 \mathrm{~mm}$. For the Antarctic sites, a smaller scan width may produce higher noise levels, whereas a greater width may integrate over too large an area, specifically if stratification is not exactly perpendicular to the scanning direction.

[35] The thickness of each couplet was calculated as the depth difference between two successive bright peaks. Accordingly, the couplets in the Weddell Sea are usually $2-5 \mathrm{~mm}$ thick with some exceptions ranging from $1-8 \mathrm{~mm}$. The average thickness is $3.0-3.5 \mathrm{~mm}$, depending on the site (for details, see Table 3). The contrast between bright and dark layers results from grain size variations as deduced from measurements conducted with the Radius tool (for method, see Seelos and Sirocko [2005]). As a result, bright layers contain higher amounts of coarser-grained silt, whereas dark layers consist of finer-grained mud.

[36] The contrast between dark and bright layers is generally low and sometimes, individual layers can hardly be distinguished. Visual counting by different individuals, for instance, revealed differences of up to $5 \%$ in the amount of layers in crucial areas. The results obtained with the PEAK tool here were always within these limits. Accordingly, gray scale scans generated with the BMPix on the Weddell Sea cores also face counting uncertainties beyond the liability of the PEAK tool.

[37] We first used the maximum count method to determine both the amount and the thickness of couplets in order to test our hypothesis that the couplets represent varves. At Site PS1789, we counted 3329 couplets between $199 \mathrm{~cm}$ and 1211 $\mathrm{cm}$ core depth (red dots in Figure 8). These two horizons are 19,223 and 22,476 cal years B.P. old according to $\mathrm{AMS}^{14} \mathrm{C}$ dating (see Table 3). Hence, the age difference of 3253 years is very close to the 3329 couplets (bright peaks) that were counted with the maximum count algorithm of PEAK. Therefore, we see strong evidence that the lamination represents annual variability and that the couplets of the Weddell Sea continental margin can be named varves. There are apparently two seasonal layers of terrigenous composition and com- parable thickness, a coarser-grained (silty) bright layer and a finer-grained (muddy) dark layer. Since the seasonal cycle, in general, is the strongest in the climatic record, it would be difficult to argue for a noncyclic process that coincidently produced the exact amount of laminae over three millennia that are required to indicate a seasonal origin. Further evaluation of the annual character of the laminae, including spectral analysis and the interpretation of a variety on nondestructive data sets, will be the focus of a follow-up paper. Also, future sedimentologic studies will include microfabrics investigation.

[38] Unfortunately, the ${ }^{14} \mathrm{C}$ ages of the LGM carry a rather large error. For the age difference of the two horizons dated in PS1789, for instance, the error is \pm 529 years according to the error propagation of the individual ${ }^{14} \mathrm{C}$ determinations (see also Table 3). Although we are confident that this error does not constrain the varve interpretation, it is certainly too large to provide a more accurate information about the duration of that time interval, that, in turn would help to improve the counting results. Also, and even more importantly, the error is also too large to answer the question how much time the few intercalated nonlaminated (mostly bioturbated) sections may contain. From the given data we have to assume that the nonlaminated intervals at Site PS1789 do not represent longer gaps.

[39] Longer gaps can be deduced from Site PS1599. Although the average laminae thickness (determined only over continuously laminated core sections) is virtually the same for Sites PS1599 and PS1789 (3.0 and $3.1 \mathrm{~mm}$, respectively (Table 3)), and although the age differences between the topmost and lowermost ${ }^{14} \mathrm{C}$ determinations are almost similar (3402 and 3253 years, respectively), the amount of bright layers is cut in half (1634 and 3329 , respectively) as well as the sedimentation rates are only $50 \%(162$ and $311 \mathrm{~cm} / \mathrm{kyr}$, respectively (Table 3$)$ ). Therefore, the three nonlaminated sections in PS1599 (371-384 cm, 552-601 cm, and 894-904 cm (see Figure 7)) must contain much more time, i.e., at least two hiatuses. Specifically the relatively long, nonlaminated section 552-601 $\mathrm{cm}$ contains several indications of discontinuous sedimentation with alterations of bioturbated and IRD-rich sections. Therefore, we consider the record of Site PS1599 rather incomplete, whereas Site PS1789 contains a more or less complete record of annual lamination.

[40] The longest and visually most complete record of lamination is documented for Site PS1791. 


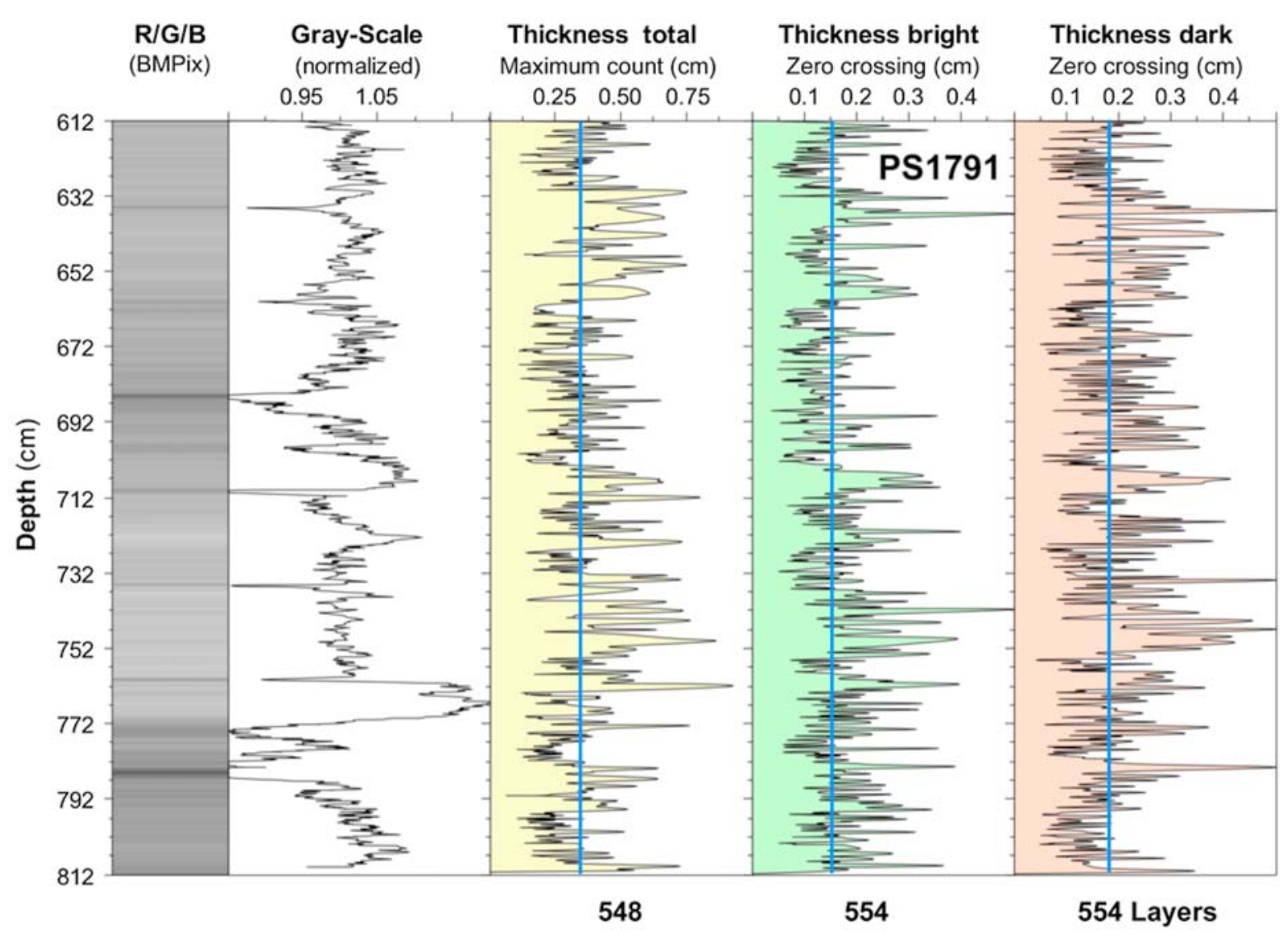

Figure 9. Selected nondestructive measurements on Site PS1791 from southeastern Weddell Sea. To the left are shown R/G/B and gray scale data generated with BMPix tool and plotted with PanPlot (M. Diepenbroek et al., PanPlot, 2001, http://www.pangaea.de/Software/PanPlot). Total layer thickness (determined with maximum count algorithm) is the thickness of a couplet. Thicknesses for dark intervals are higher and more variable on average than for bright layers (both determined with the zero crossing algorithm).

Although we could not collect enough planktonic specimens of Neogloboquadrina pachyderma to allow for $\mathrm{AMS}^{14}$-C dating, there are only three tiny sections within the LGM that are not laminated. The maximum count algorithm of PEAK counted 3002 couplets (Table 3 ). Hence, we presume, as for Site PS1789, an almost continuous record of three millennia during the LGM. Generally, the laminae are slightly more distinct and somewhat thicker (3.5 $\mathrm{mm}$ on average) than at Sites PS1599 and PS1789. Hence, the derived sedimentation rates ( $350 \mathrm{~cm} / \mathrm{kyr}$ during the LGM) would be the highest among the sites. Therefore, we used Site PS1791 to apply the zero-crossing method of PEAK over the entire core. Although this program relies on an entirely different set of settings (the moving average has to be calculated over much longer core distances and halfway crossings, not maxima, have to be count; examples for the methods are also shown in Figures 4-6), the zero-crossing method is in very good agreement with the maximum count method for the entire Site PS1791 (6000 counts, i.e., 3000 running years, compared to 3002 years, respectively; see also Table 3). Figure 9 displays a $2 \mathrm{~m}$ section of Site PS1791 with slight counting differences of about 1\% (548 couplets from the maximum count algorithm versus 554 dark and 554 bright layers from the zero-crossing algorithm).

[41] Climate records that show, for instance, a pronounced season with a distinct peak, and a less pronounced remaining record of annual sedimentation (with one or more additional seasons), might not be suitable for the zero-crossing algorithm. However, for the records from the Weddell Sea continental margin, the zero-crossing method was able to retrieve two distinct seasonal layers that can be studied independently for thickness variation. At Site PS1791 (Figure 9), the dark laminae are thicker on average than the bright laminae $(0.19 \mathrm{~mm}$ compared to $0.16 \mathrm{~mm}$ ). Also, the internal variability is 
about $10 \%$ higher for the dark laminae. In other words, follow-up studies using spectral analysis can now test whether the dark or the bright laminae, or only the annual combination of the two, contains distinct climate signals that propagate through time.

[42] With respect to regional sedimentologic and paleoceanographic aspects, the distribution of the average laminae thickness can be described as follows: the presumed source area for sediment supply is the area north of Filchner Trough and its prolongation, the northeastern Crary Fan [Kuvaas and Kristoffersen, 1991; Weber et al., 1994]. Site PS1789 is located on the southernmost sediment ridge that is larger and located closer to the source than the ridge Site PS1599 is located on. Therefore, it is natural to assume that Site PS1789 received more sediment during the LGM and the laminae are somewhat thicker. Site PS1791 is also located on the southernmost sediment ridge further northeast at the confluence of three channels, which is why it may have received the thickest and most distinct varves. This interpretation is corroborated by sediment echosounding investigations [see Kuhn and Weber, 1993], which indicate deeper acoustic penetration, and hence higher presumed sedimentation rates, for Site PS1791.

\section{Concluding Remarks}

[43] There are a number of different approaches in the literature to detect and count laminae. Many focus on specific aspects such as layer [e.g., Meyer et al., 2006] and structure recognition [Tiljander et al., 2002] or gray scale generation [e.g., Schaaf and Thurow, 1994; Nederbragt and Thurow, 2001b]. Even though we may lack some of the sophisticated abilities of other programs, our approach combines the important steps in a very straightforward and highly iterative manner to provide the results necessary for paleoclimate research:

[44] First, we do not attempt to recognize laminae directly from digital images with all the potential pitfalls implicated; instead, we simply generate gray scale (or color) curves from which the layers are identified based on objective and reproducible mathematical criteria.

[45] Second, we apply fully automated counting algorithms. So far, other approaches, specifically those focusing on tree rings, still rely on manual counting, which is vulnerable for counting errors in a variety of ways.
[46] Third, along with the amount of laminae, the PEAK algorithms also measure the thickness of each layer and associate it with a depth in core, an important prerequisite to conduct spectral analysis in order to learn how climate signals propagate through time. The maximum count algorithm provides a thickness for each year, whereas the zerocrossing algorithm measures the thickness of an individual season.

[47] Fourth, the whole process is highly interactive with a focus on visualization. The gray scale curve generated with BMPix is directly displayed onto the image that also contains the line along which the profile has been generated: the X-radiograph (Weddell Sea) or photo (Saanich Inlet). Here, the macros clearly benefit from the tight integration into Microsoft Excel with its visualization and data processing capabilities. Therefore, visual control, and, if necessary, readjustment of settings and rerun of gray scale generation can be made easily and precisely. The counts determined later by the PEAK tools are then displayed onto the gray scale curve as vertical bars (e.g., Figures 3-6). At this final stage, all information necessary to evaluate the quality of the calculation is available visually: the gray scale curve (or moving average that has been calculated), the peaks that have been counted, and the underlying image with the profile line. Again, settings can be changed quickly to rerun PEAK with optimized settings. Accordingly, a number of iterations can be achieved in a short period of time, which contributes significantly to error reduction in the counting process. The optimization can be applied individually to images of a site, or, since all images of a site are kept in separate spreadsheets of a single Excel workbook, the changes can be applied to all spreadsheets simultaneously by executing another macro; that is, all laminae of the core can be recounted with a single command and in a matter of seconds to minutes. Of course it is recommended to recheck all spreadsheets visually for overcount and undercount laminae. This step is not very time consuming and also serves as quality assurance.

[48] The fact that, in practice, a sedimentary record has to be segmented into many slices before it can be processed for gray scale recognition and successive counting, leads to systematic undercount of layers. For instance, the Weddell Sea cores were retrieved in consecutive plastic liners of $5 \mathrm{~m}$ length. Onboard, these liners were cut into $1 \mathrm{~m}$ sections. Each section then was divided into $4 \mathrm{X}$-radiograph slices. Site PS1789, for instance, was retrieved in 3 liners, cut into 15 sections and 60 slices. This 
procedure ultimately leads to missing sediment parts (layers) at the top and bottom of each plastic liner, section, and slice. Current logging systems such as line scan cameras or tomographic imaging tools improve the situation by providing continuous information over longer intervals (i.e., $1-1.5 \mathrm{~m}$ ).

\section{Summary}

[49] We presented new tools that allow for rapid and quantitative detection of sediment lamination. The software consists of a set of Visual Basic macros that are executed from within Microsoft Excel. The first tool (BMPix) generates color and gray scale curves from any given BMP image. The resulting curves are of ultrahigh $(\mu \mathrm{m})$ resolution, an essential prerequisite for the following steps. The second tool (PEAK) uses the gray scale curve and performs, for the first time, fully automated and visually comprehensible counting of laminae. Depending on the type of sediment and the desired investigation, there are three choices. The maximum count algorithm counts every bright peak of a couplet, based on the calculation of a narrow moving average of the gray scale curve, and the definition of a minimum height and length of a peak. The zero-crossing algorithm counts every halfway passage of the gray scale curve through a wide moving average, thereby separating bright from dark intervals. The frequency truncation algorithm also counts halfway passages, but instead of subtracting the moving average before counting, the high- and low-frequency components are removed first.

[50] The first tests concerning the liability of the new tools were carried out on tree rings, where lamination is easy to recognize. Accordingly, gray scale generation and counting algorithms provided robust results. The following tests concentrated on well-dated and already manually counted marine varves from Saanich Inlet. These marine laminae are also rather regular in shape and the difference between the maximum count algorithm and manual counts is less than $2 \%$.

[51] Then we applied the tools to the rather complex laminae detected in marine sediment from Antarctica. At the Weddell Sea continental margin, several sites indicate more or less continuously laminated sequences over several millennia during the LGM. Here, the uncertainty of the PEAK tool is within the uncertainty of manual counts $(\geq 5 \%)$. In combination with $\mathrm{AMS}^{14} \mathrm{C}$ dating of marine car- bonates, we found strong evidence that the lamination represents true varves. There are apparently two seasonal layers, a coarser-grained bright layer and a finer-grained dark layer. The dark layers are, on average, thicker and contain higher variability relative to the bright layers, as detected with the zero-crossing algorithm. Unfortunately, the errors in the ${ }^{14} \mathrm{C}$ dating are too large to provide additional information on the duration of partially intercalated, nonlaminated (mostly bioturbated) intervals.

[52] The new laminae recognition and counting tools offer a number of advantages over previous tools and manual counting. Since the counting procedures are based on a moving average that has been generated from gray scale curves, the results are highly objective and rely on reproducible mathematical criteria. Also, since all counts associate an annual peak (or a season) with a specific depth, the thickness of each year (or each season) is also measured and can be used for later paleoclimate-related evaluation (e.g., time series analysis). In addition, the tight integration into Microsoft Excel allows for taking advantage of the visualization and data processing capabilities of the software. In this context, all information required for the analysis is displayed graphically and numerically on screen just seconds after the macros have been executed. Therefore, and that is the most decisive advantage, the new tools are highly interactive and allow for fast and precise optimization of the rules that are applied to the counting procedure.

\section{Acknowledgments}

[53] We wish to thank Editor Vincent Salters and coeditor Frits Hilgen for their continued support during the publication process. Also, two anonymous reviewers helped to improve the manuscript. The Deutsche Forschungsgemeinschaft (DFG) (grants Ri 525/17-1 and Ku 683/9-1) is acknowledged for supporting this project financially. Frank Sirocko kindly measured samples with the Radius Tool for grain size distribution. Bernhard Weninger was very helpful in discussing the $\mathrm{AMS}^{14} \mathrm{C}$ data. Rita Fröhlking and Susanne Wiebe are acknowledged for their laboratory assistance. Our study is part of the Southern Ocean Initiative of the International Marine Past Global Change Study (IMAGES) program. All data of this paper will be made available at the PANGAEA Network for Geological and Environmental Data (thanks to H. Grobe, M. Diepenbroek, and R. Sieger) hosted by the Alfred-WegenerInstitute for Polar and Marine Research (http://www.pangaea.de/ PHP/References.php?q=mweber). The software tools introduced here are available at doi:10.1594/PANGAEA.729700. 


\section{References}

Anderson, J. B., R. Wright, and B. Andrews (1986), Weddell Fan and associated abyssal plain, Antarctica: Morphology, sediment processes, and factors influencing sediment supply, Geo Mar. Lett., 6, 121-129, doi:10.1007/BF02238082.

Berkman, P. A., and S. L. Forman (1996), Pre-bomb radiocarbon and the reservoir correction for calcareous marine species in the Southern Ocean, Geophys. Res. Lett., 23(4), 363-366, doi:10.1029/96GL00151.

Boes, X., N. Piotrowskac, and N. Fagela (2005), High-resolution diatom/clay record in Lake Baikal from grey scale, and magnetic susceptibility over Holocene and Termination I, Global Planet. Change, 46, 299-313, doi:10.1016/j. gloplacha.2004.09.025.

Bornhold, B., et al. (1998), Proceedings of the Ocean Drilling Program, Initial Reports, vol. 169S, Ocean Drill. Program, College Station, Tex.

Domack, E. W., M. Taviani, and A. Rodriguez (1999), Recent sediment remolding on a deep shelf, Ross Sea: Implications for radiocarbon dating of Antarctic marine sediments, Quat. Sci. Rev., 18(13), 1445-1451, doi:10.1016/S0277-3791(99) 00042-6.

Elverhøi, A. (1981), Evidence for the late Wisconsin glaciation of the Weddell Sea, Nature, 293, 641-642, doi:10.1038/ $293641 \mathrm{a} 0$.

Elverhøi, A. (1984), Glacigenic and associated marine sediments in the Weddell Sea, fjords of Spitzbergen and the Barents Sea: A review, Mar. Geol., 57, 53-88, doi:10.1016/0025-3227(84)90195-6.

Fütterer, D. K., and M. Melles (1990), Sediment patterns in the southern Weddell Sea: Filchner Shelf and Filchner Depression, in Geological History of the Polar Oceans: Arctic Versus Antarctic, edited by U. Bleil and J. Thiede, pp. 381-401, Kluwer Acad., Dordrecht, Netherlands.

Fütterer, D. K., H. Grobe, and S. Grünig (1988), Quaternary sediment patterns in the Weddell Sea: Relations and environmental conditions, Paleoceanography, 3(5), 551-561, doi:10.1029/PA003i005p00551.

Gebco (1983), General bathymetric chart of the oceans, 5-18, polar stereo projection $1: 6,000,000$, at $75^{\circ} \mathrm{S}$ latitude, Can. Hydrogr. Serv., Ottawa, Ont., Canada.

Gordon, J. E., and D. Harkness (1992), Magnitude and geographic variation of the radiocarbon content in Antarctic marine life: Implications for reservoir corrections in radiocarbon dating, Quat. Sci. Rev., 11, 697-708, doi:10.1016/ 0277-3791(92)90078-M.

Hughen, K., S. Lehman, J. Southon, J. Overpeck, O. Marchal, C. Herring, and J. Turnbull (2004a), ${ }^{14} \mathrm{C}$ activity and global carbon cycle changes over the past 50000 years, Science, 303, 202-207, doi:10.1126/science. 1090300 .

Hughen, K. A., et al. (2004b), Marine04 Marine radiocarbon age calibration, 26-0 ka BP, Radiocarbon, 46, 1059-1086.

Hughen, K., J. Southon, S. Lehman, C. Bertrand, and J. Turnbull (2006), Marine-derived ${ }^{14} \mathrm{C}$ calibration and activity record for the past 50,000 years updated from the Cariaco Basin, Quat. Sci. Rev., 25(23-24), 3216-3227, doi:10.1016/j.quascirev. 2006.03.014.

Kemp, A. E. S. (1996), Laminated sediments as paleo-indicators, in Palaeoclimatology and Palaeoceanography From Laminated Sediments, edited by A. E. S. Kemp, Geol. Soc. Spec. Publ., 116, vii-xii.

Knutti, R., J. Flückiger, T. F. Stocker, and A. Timmermann (2004), Strong hemispheric coupling of glacial climate through freshwater discharge and ocean circulation, Nature, 430, 851-856, doi:10.1038/nature02786.

Kuhn, G., and M. E. Weber (1993), Acoustical characterization of sediments by Parasound and $3.5 \mathrm{kHz}$ systems: Related sedimentary processes on the southeastern Weddell Sea continental slope, Antarctica, Mar. Geol., 113, 201-217, doi:10.1016/ 0025-3227(93)90018-Q.

Kuvaas, B., and Y. Kristoffersen (1991), The Crary Fan: A trough-mouth fan on the Weddell Sea continental margin, Antarctica, Mar. Geol., 97, 345-362, doi:10.1016/00253227(91)90125-N.

Melles, M. (1991), Late Quaternary paleoglaciology and paleoceanography at the continental margin of the southern Weddell Sea, Antarctica, Ber. Polarforsch., 81, 190 pp., Alfred-Wegener-Inst. für Polar- und Meeresforsch., Bremerhaven, Germany.

Melles, M., and G. Kuhn (1993), Sub-bottom profiling and sedimentological studies in the southern Weddell Sea, Antarctica: Evidence for large-scale erosional/depositional processes, Deep Sea Res., 40(4), 739-760, doi:10.1016/0967-0637(93) 90069-F.

Meyer, M. C., R. Faber, and C. Spötl (2006), The WinGeol lamination tool: New software for rapid, semi-automated analysis of laminated climate, Holocene, 16(5), 753-761, doi:10.1191/0959683606h1969rr.

Michels, K. H., G. Kuhn, C.-D. Hillenbrand, B. Diekmann, D. K. Fütterer, H. Grobe, and G. Uenzelmann-Neben (2002), The southern Weddell Sea: Combined contouriteturbidite sedimentation at the southeastern margin of the Weddell Gyre, in Deep-Water Contourite Systems: Modern Drifts and Ancient Series, Seismic and Sedimentary Characteristics, edited by D. A. V. Stow et al., Geol. Soc. London Mem., 22, 305-323.

Nederbragt, A. J., and J. Thurow (2001a), Sediment color variation and annual accumulation rates in laminated Holocene sediments, Site 1098, Palmer Deep, Proc. Ocean Drill. Program Sci. Results, 178, 1-20.

Nederbragt, A. J., and J. Thurow (2001b), A 6000 yr varve record of Holocene climate in Saanich Inlet, British Columbia, from digital sediment colour analysis of ODP Leg 169S cores, Mar. Geol., 174, 95-110, doi:10.1016/S0025-3227(00) 00144-4.

Reichelt, L. (2007), Entwicklung neuer Methoden zur hochauflösenden Untersuchung von Umweltvariationen an spätquartären Sedimenten aus dem Weddellmeer, Antarktis, MSc thesis, 123 pp., Univ. of Cologne, Cologne, Germany.

RinnTech (2002), LignoVision ${ }^{\mathrm{TM}}$ Scientific software for automated tree-ring measurements and density profiling v. 1.3.2 - Software manual, Heidelberg, Germany. (Available at http://www.rinntech.de)

Schaaf, M., and J. Thurow (1994), A fast and easy method to derive highest-resolution time-series data sets from drillcores and rock samples, Sediment. Geol., 94, 1-10, doi:10.1016/0037-0738(94)90143-0.

Seelos, K., and F. Sirocko (2005), RADIUS-Rapid particle analysis of digital images by ultra-high-resolution scanning of thin sections, Sedimentology, 52, 669-681, doi:10.1111/ j.1365-3091.2005.00715.x.

Staubwasser, M., G. Henderson, P. A. Berkman, and B. L. Hall (2004), $\mathrm{Ba}, \mathrm{Ra}, \mathrm{Th}$, and $\mathrm{U}$ in marine mollusk shells and the potential of ${ }^{226} \mathrm{Ra} / \mathrm{Ba}$ dating of Holocene marine carbonate shells, Geochim. Cosmochim. Acta, 68(1), 89-100, doi:10.1016/S0016-7037(03)00279-5. 
Stocker, T. F., and S. J. Johnsen (2003), A minimum thermodynamic model for the bipolar seesaw, Paleoceanography, 18(4), 1087, doi:10.1029/2003PA000920.

Stuiver, M., G. H. Denton, T. J. Hughes, and J. L. Fastook (1981), History of the marine ice sheet in west Antarctica during the last glaciation: A working hypothesis, in The Last Great Ice Sheets, edited by G. H. Denton and T. J. Hughes, pp. 319-436, John Wiley, New York.

Tiljander, M., A. Ojala, T. Saarinen, and I. Snowball (2002), Documentation of the physical properties of annually laminated (varved) sediments at a sub-annual to decadal resolution for environmental interpretation, Quat. Int., 88, 5-12, doi:10.1016/S1040-6182(01)00068-4.

Wang, Y. J., H. Cheng, R. L. Edwards, Z. S. An, J. Y. Wu, C.-C. Shen, and J. A. Dorale (2001), A high-resolution absolutedated late Pleistocene monsoon record from Hulu Cave, China, Science, 294, 2345-2348, doi:10.1126/science. 1064618.
Weber, M. E., G. Bonani, and K. D. Fütterer (1994), Sedimentation processes within channel-ridge systems, southeastern Weddell Sea, Antarctica, Paleoceanography, 9(6), 1027 1048, doi:10.1029/94PA01443.

Wright, R., J. B. Anderson, and P. P. Fisco (1983), Distribution and association of sediment gravity flow deposits and glacial/glacial marine sediments around the continental margin of Antarctica, in Glacial-Marine Sedimentation, edited by B. F. Molnia, pp. 265-300, Plenum, New York.

Zolitschka, B. (1996), High resolution lacustrine sediments and their potential for paleoclimate reconstruction, in Climatic Variations and Forcing Mechanisms of the Last 2000 Years, NATO ASI Ser., Ser. I, vol. 41, edited by D. P. Jones, R. S. Bradley, and J. Jouzer, pp. 444-478, Springer, Berlin. 